\title{
Effect of amiodarone and dronedarone administration in rats on thyroid hormone-dependent gene expression in different cardiac components
}

\author{
I Stoykov $^{1,2}$, H C van Beeren ${ }^{1}$, A F M Moorman ${ }^{2}$, V M Christoffels ${ }^{2}, \mathrm{~W}$ M Wiersinga ${ }^{1}$ and O Bakker ${ }^{1}$ \\ Department of ${ }^{1}$ Endocrinology and Metabolism and ${ }^{2}$ Anatomy and Embryology, Academic Medical Center, University of Amsterdam, Meibergdreef 9 , \\ 1105 AZ Amsterdam, The Netherlands \\ (Correspondence should be addressed to O Bakker; Email: o.bakker@amc.uva.nl)
}

\begin{abstract}
Objective: In view of their different actions on thyroid hormone receptor (TR) isoforms we set out to investigate whether amiodarone (AM) and dronedarone (Dron) have different and/or componentspecific effects on cardiac gene expression.

Design: Rats were treated with AM or Dron and the expression of TR $\alpha 1$, TR $\alpha 2$, TR $\beta 1$ and several triiodothyronine (T3)-regulated genes was studied in different parts of the heart, namely the right atrium (RA), left ventricular wall (LVW) and apex.

Methods: Rats were treated for 14 days with $100 \mathrm{mg} / \mathrm{kg}$ body weight AM or Dron. The expression of TR $\alpha 1, T R \alpha 2$, TR $\beta 1$ and T3-regulated genes was studied using real-time PCR and non-radioactive in situ hybridisation.

Results: AM and Dron affected TR expression in the RA similarly by decreasing TR $\alpha 1$ and $\beta 1$ expression by about $50 \%$. In the LVW, AM and Dron decreased TR $\beta 1$ and, interestingly, AM increased TR $\alpha 1$. In the apex, AM also increased TR $\alpha 2$. The changes seen in T3-dependent gene expression are reminiscent of foetal reprogramming.

Conclusion: Taken together, our results indicate that AM and Dron have similar effects on the expression of TR isoforms in the RA, which could partly contribute to their ability to decrease heart rate. On the other hand, the more profound effect of AM appears on TR- and T3-dependent gene expression in the left ventricle suggests foetal reprogramming.
\end{abstract}

European Journal of Endocrinology 156 695-702

\section{Introduction}

Thyroid hormone (TH) has profound effects on the heart via the different $\mathrm{TH}$ receptor isoforms, for example as a chronotrope. Specialised cells generate the rhythm and guide the impulse throughout the heart. The conduction system can be divided into the sino-atrial node (SAN), the atrioventricular node $(\mathrm{AVN})$ and the peripheral ventricular conduction system (PVCS). From our recent studies, it has become apparent that the $\mathrm{TH}$ receptor (TR) isoforms $\alpha 1, \alpha 2$ and $\beta 1$ are expressed in a component-specific manner in the heart (2). In the mouse, it has been found that TR $\alpha 1$ is important in setting heart rhythm and regulating the expression of genes important for cardiac function such as $\alpha$-myosin heavy chain ( $\alpha \mathrm{MHC}$; up-regulated by TH), $\beta \mathrm{MHC}$ (downregulation reciprocal to $\alpha \mathrm{MHC}$ ), sarcoplasmic reticulum Ca-ATPase2a (SERCA2a; up-regulated by TH) and guanine nucleotide regulatory proteins (like HCN4; up-regulated by TH; $(3,4))$. Furthermore, TR $\beta 1$ appears to have a function in mediating the tri-iodothyronine $\left(\mathrm{T}_{3}\right)$-induced increase in the heart rate in the mouse (5).
The situation is slightly different in the rat where it has been suggested that TR $\beta 1$ also plays a role in the expression of SERCA2a and $\beta$ MHC $(6,7)$.

We speculated whether the component-specific expression of TRs had any relation to certain TH antagonistic effects of the class III anti-arrhythmic drugs amiodarone (AM) and dronedarone (Dron). AM has been suggested to induce a localised hypothyroid condition in the heart (8), which is partly due to its TR inhibiting action $(9,10)$. Similarly Dron also appears to mimic hypothyroidism at the level of the heart $(6,11)$. Furthermore, it has been shown that a high dose of AM intensifies cardiac remodelling (12). Remodelling after cardiac failure by itself has been suggested to bring about a hypothyroid cardiac phenotype with accompanying changes in TR expression as well as changes in the expression of genes like SERCA (13). In the present study, we look at a combination of both phenomena on the expression of the TR isoforms $\alpha 1, \alpha 2$ and $\beta 1$, and the $\mathrm{T}_{3}$-dependent genes $\alpha$ and $\beta M H C$, SERCA2a, guanine nucleotide regulatory protein (HCN4) and atrial natriuretic factor (ANF) in the different components of the rat heart. 


\section{Materials and methods}

\section{In vivo studies}

Male Wistar rats, divided into three groups (eight rats per group), were housed under normal conditions with free access to standard lab chow and tap water. The rats received either water (controls), an aqueous suspension of Dron $100 \mathrm{mg} / \mathrm{kg}$ body weight or AM $100 \mathrm{mg} / \mathrm{kg}$ body weight by gastric tubes daily for 2 weeks as described previously (11). Rats were anaesthetised and killed by i.p. infusion of $0.5 \mathrm{mg} / \mathrm{kg}$ medetomidine (Dormitor $1 \mathrm{mg} / \mathrm{ml}$ ) and $0.75 \mathrm{mg} / \mathrm{kg}$ ketamine (Ketalar $10 \mathrm{mg} / \mathrm{ml}$ ). Blood was collected by cardiac puncture and plasma was stored at $-20{ }^{\circ} \mathrm{C}$. The hearts were removed and washed in PBS. Five hearts of each group were dissected under a stereomicroscope into right atria, part of the left ventricle wall and cardiac apex. These components were immediately frozen and stored in liquid nitrogen for isolation of mRNA. Three hearts were washed in PBS and processed for in situ hybridisation. The animal experiments were approved by the animal welfare committee of the Academic Medical Centre, University of Amsterdam.

\section{Plasma assays}

Total thyroxine $\left(\mathrm{T}_{4}\right)$ and $\mathrm{T}_{3}$ were measured by an in-house RIA (14), using rat null plasma as diluent. TSH was determined by Delfia fluoroimmunoassay (Perkin-Elmer Wallac GmbH, Freiburg, Germany). Plasma total cholesterol was measured using a fully enzymatic dye method (Modular P analyzer, Roche Molecular Biochemicals). All samples were measured in one run. Data are expressed as mean \pm s.D.

\section{mRNA analyses by real-time PCR}

mRNA from the right atrium (RA), apex and left ventricular wall (LVW) was obtained with the MagNa Pure LC RNA Isolation Kit II (Tissue; Roche) using the MagNa Pure LC Instrument (Roche), after which cDNA was made using the first-strand cDNA synthesis kit (containing avian myeloblastosis virus (AMV) reverse transcriptase) on which real-time PCR was performed using the LightCycler (Roche). Primers were purchased from Biolegio BV (Malden, The Netherlands). TR $\alpha 1$ and $\mathrm{TR} \propto 2$ were quantified as described previously (15). For
TR $\beta 1$, primer sequences were as follows: forward, 5'-CACCTGGATCCTGACGATGT-3' and reverse, 5'-ACAGGTGATGCAGCGATAGT-3'. SERCA2a was detected using the following primers: forward, 5'-ATGGACGAGACGCTCAAGTT-3'; reverse, 5'-GAAGCGGTTACTCCAGTATTGC-3'; ANF using forward, 5'-AACACAGATCTGATGGATTTCAAG-3'; reverse, 5'-CGCTTCATCGGTCTGCTC-3'; $3^{\prime}$ MHC using forward, 5'-CTGCAGTCAGCCCTGGAG-3'; reverse, 5'-GGAGGATCTTGCCCTCCT3'; $\beta M H C$ using forward, 5'-CATCAAGGAGCTCACCTACCA-3'; reverse, 5'-TCCTGCAGTCGCAGTAGGTT-3'; and finally HCN4 using forward, 5'-ATCCAGTCGCTGGACTCCT-3'; reverse, 5'-TGTACTGCTCCACCTGCTTG-3'.

\section{Non-radioactive in situ hybridisation for $T_{3}$-regulated genes}

The hearts were processed for in situ hybridisation using a fixation protocol and digoxigenin (DIG)-labelled, single-strand RNA probes as described previously (16). All probes have also been described previously: SERCA2a (17), $\alpha \mathrm{MHC}$ and $\beta \mathrm{MHC}$ (18), HCN4 (19) and ANF (20). Images of sections were taken using a digital camera Leica DFC 320 RZ 0793, coupled with a Zeiss Axiophot microscope, equipped with differential interference contrast optics.

\section{Statistical analysis}

Differences between groups in plasma TH parameters and body weights were evaluated using ANOVA followed by a t-test when the ANOVA appeared significant to identify individual changes. Differences between groups in mRNA levels were evaluated using the Mann-Whitney test.

\section{Results}

\section{Plasma parameters and body weight}

To confirm the efficacy of the drug treatment, we checked several plasma parameters (Table 1). As expected, AM-treated animals had higher $\mathrm{T}_{4}$, TSH and total cholesterol and lower $\mathrm{T}_{3}$ plasma concentrations than either Dron-treated animals or controls (11). Body weight

Table 1 Plasma parameters and body weight (BW).

\begin{tabular}{|c|c|c|c|c|}
\hline & Control & Dron & AM & ANOVA $(P)$ \\
\hline TSH (ng/ml) & $2.11 \pm 0.80$ & $1.45 \pm 0.75$ & $6.70 \pm 3.39^{*}$ & $<0.0001$ \\
\hline $\mathrm{T}_{4}(\mathrm{nmol} / \mathrm{l})$ & $72 \pm 10$ & $68 \pm 14$ & $150 \pm 21^{*}$ & $<0.0001$ \\
\hline $\mathrm{T}_{3}(\mathrm{nmol} / \mathrm{l})$ & $1.21 \pm 0.13$ & $1.09 \pm 0.19$ & $0.78 \pm 0.11^{*}$ & $<0.0001$ \\
\hline Total cholestrol (mmol/l) & $1.94 \pm 0.26$ & $1.95 \pm 0.25$ & $2.89 \pm 0.53^{*}$ & $<0.0001$ \\
\hline Baseline BW (g) & $287 \pm 9$ & $295 \pm 9$ & $288 \pm 7$ & N.S. \\
\hline$\Delta \mathrm{BW}(\mathrm{g})$ & $64 \pm 13$ & $58 \pm 7$ & $41 \pm 11^{*}$ & $<0.0001$ \\
\hline
\end{tabular}

Values are represented as mean \pm S.D. ${ }^{\star} P<0.01$ versus controls. 
gain during the experiment in the AM-treated animals was lower compared with the Dron-treated group and controls.

\section{Cardiac component-specific TR gene expression}

We studied the mRNA expression of TR isoforms $\alpha 1, \alpha 2$ and $\beta 1$ in three parts of the heart, which represent different cardiac components, namely the RA (including the SAN), the LVW (mainly working myocardium) and the apex (contains a large proportion of PVCS). Dron caused a decreased expression of TR $\alpha 1$ in the RA but had no effect in the LVW or apex. TR $\alpha 2$ expression was not influenced by Dron. TR $\beta 1$ expression in RA, LVW and apex was decreased by Dron (Fig. 1). AM lowered TR $\alpha 1$ expression in the RA, but interestingly increased it in the LVW. In the apex, no change was seen in TR $\alpha 1$, but TR $\alpha 2$ increased as a result of AM (Fig. 1). TR $\beta 1$ expression was decreased by AM in all the three components (Fig. 1).

\section{TR-regulated cardiac genes}

The same parts of the rat heart were also used to quantify mRNA expression by PCR of a number of $\mathrm{T}_{3}$-dependent genes after AM or Dron treatment, in parallel with visualisation using in situ hybridisation. From the latter experiments, it appears that in the control animals, SERCA2a and aMHC are expressed throughout the heart. ANF is expressed in the atria, apex and PVCS
Right atrium
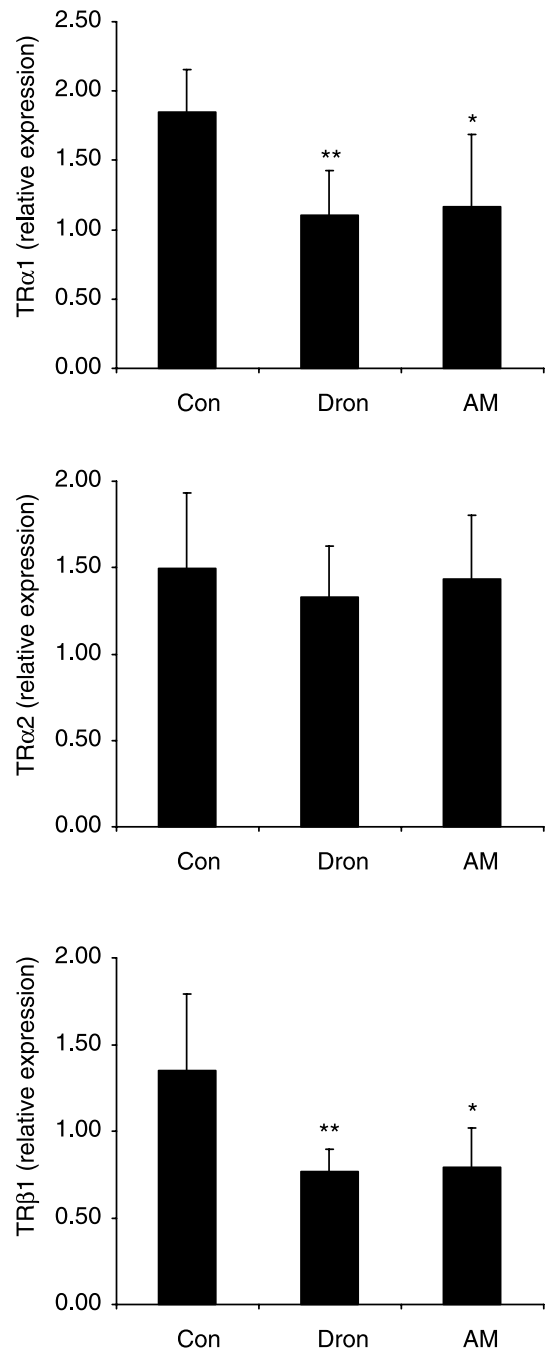

Left ventricular wall
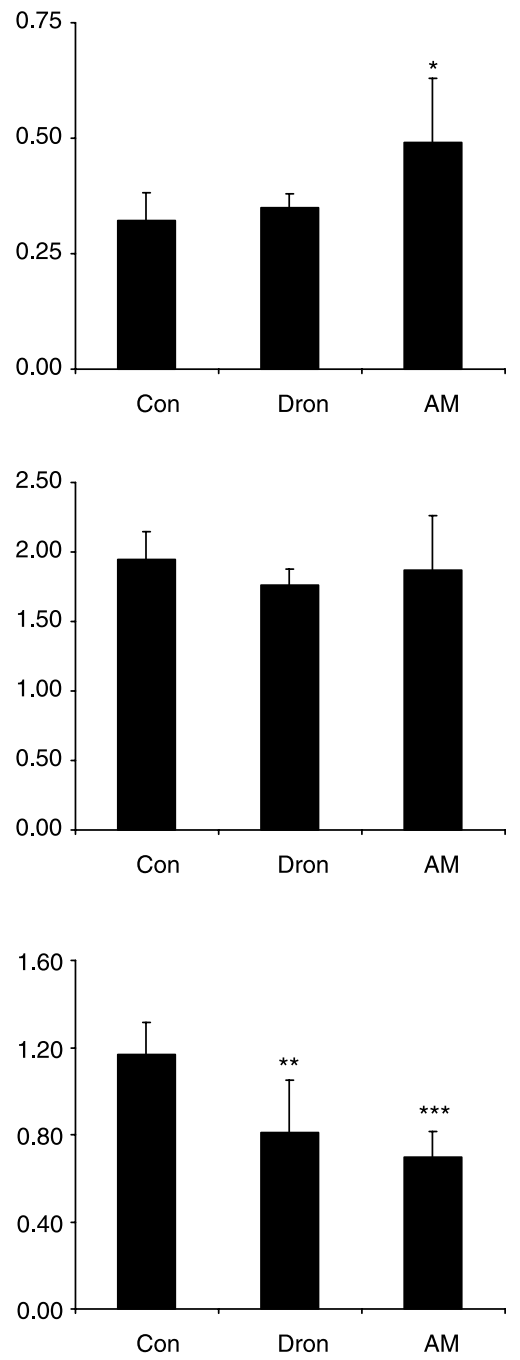

Apex
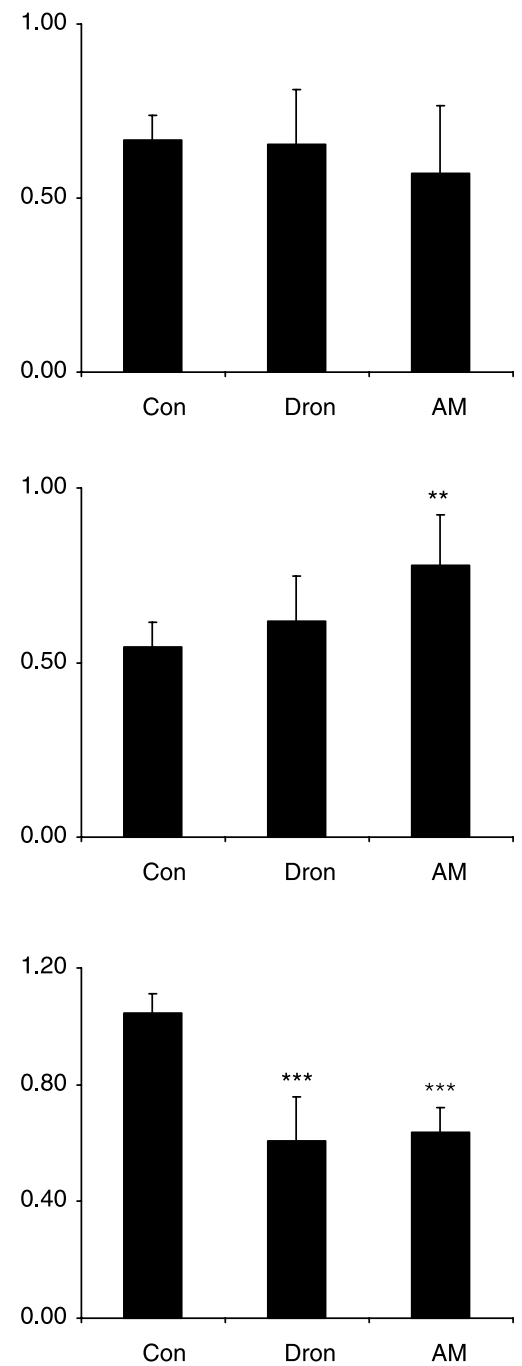

Figure 1 Expression of the TR isoforms $\alpha 1, \alpha 2$ and $\beta 1$ in different cardiac components. The mRNA values of control, AM- and Dron-treated rats are corrected for GAPDH and presented as mean \pm s.D. ${ }^{*} P<0.05,{ }^{* \star} P<0.01$ and ${ }^{* \star \star} P<0.001$ versus controls. 
(Figs 3 and 4). Although $\alpha \mathrm{MHC}$ is expressed throughout the heart, $\beta \mathrm{MHC}$ is found only in the PVCS. HCN4 showed positive staining only in the SAN.

Dron treatment caused a decrease in $\alpha \mathrm{MHC}$ expression in the cardiac apex and shows a trend towards decreased ANF expression in the LVW (Fig. 2). None of the other genes studied were affected by Dron treatment. This is reflected in the in situ hybridisation results as shown in Fig. 3. SERCA2a expression in the RA showed a trend towards a decrease due to AM treatment $(P<0.1)$. AM increased ANF expression in the apex (Figs 3 and 4). Furthermore, it caused a reciprocal regulation of $\alpha \mathrm{MHC}$ and $\beta \mathrm{MHC}$ in this component; $\alpha \mathrm{MHC}$ showed a trend towards a decrease in the RA $(P<0.1)$ and decreased in the apex, whereas $\beta M H C$ increased in both the components. No difference between the effect of AM and Dron on $\alpha \mathrm{MHC}$ expression in the apex was observed. The same observations can be made looking at the in situ hybridisation data (Fig. 3). We did not observe any significant differences in the expression of HCN4 in the RA after AM or Dron treatment (mRNA data not shown; Fig. 4).
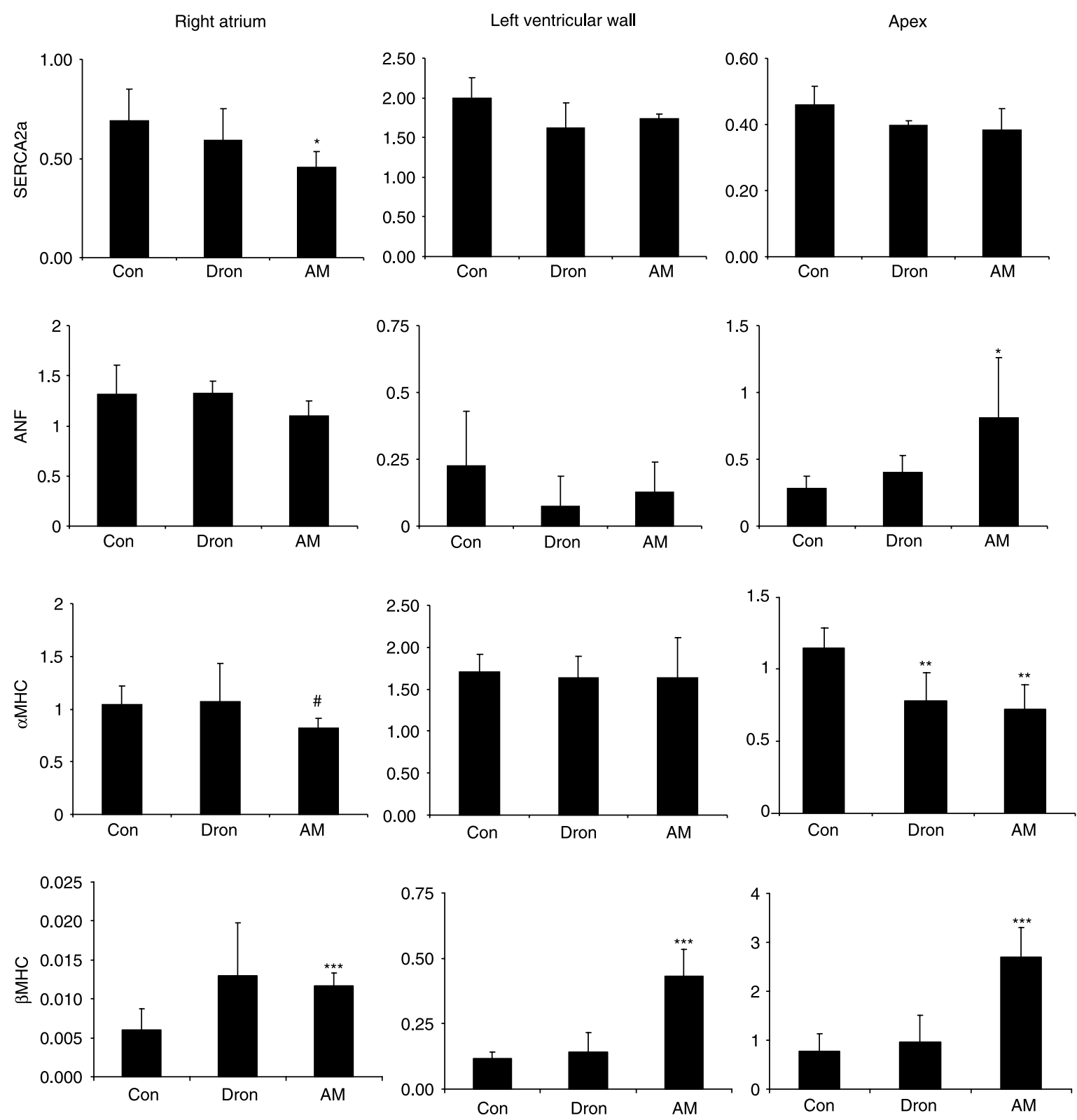

Figure 2 Expression of thyroid hormone-regulated genes in components of the rat heart. $\alpha \mathrm{MHC}, \beta \mathrm{MHC}, \mathrm{SERCA2a}, \mathrm{HCN} 4$ and ANF were measured in mRNA derived from different cardiac components of control, AM- and Dron-treated rats. Values are corrected for GAPDH and presented as mean \pm s.D. ${ }^{\#} P<0.1,{ }^{\star} P<0.05,{ }^{\star \star} P<0.02$ and ${ }^{\star \star \star} P<0.01$ versus controls. 

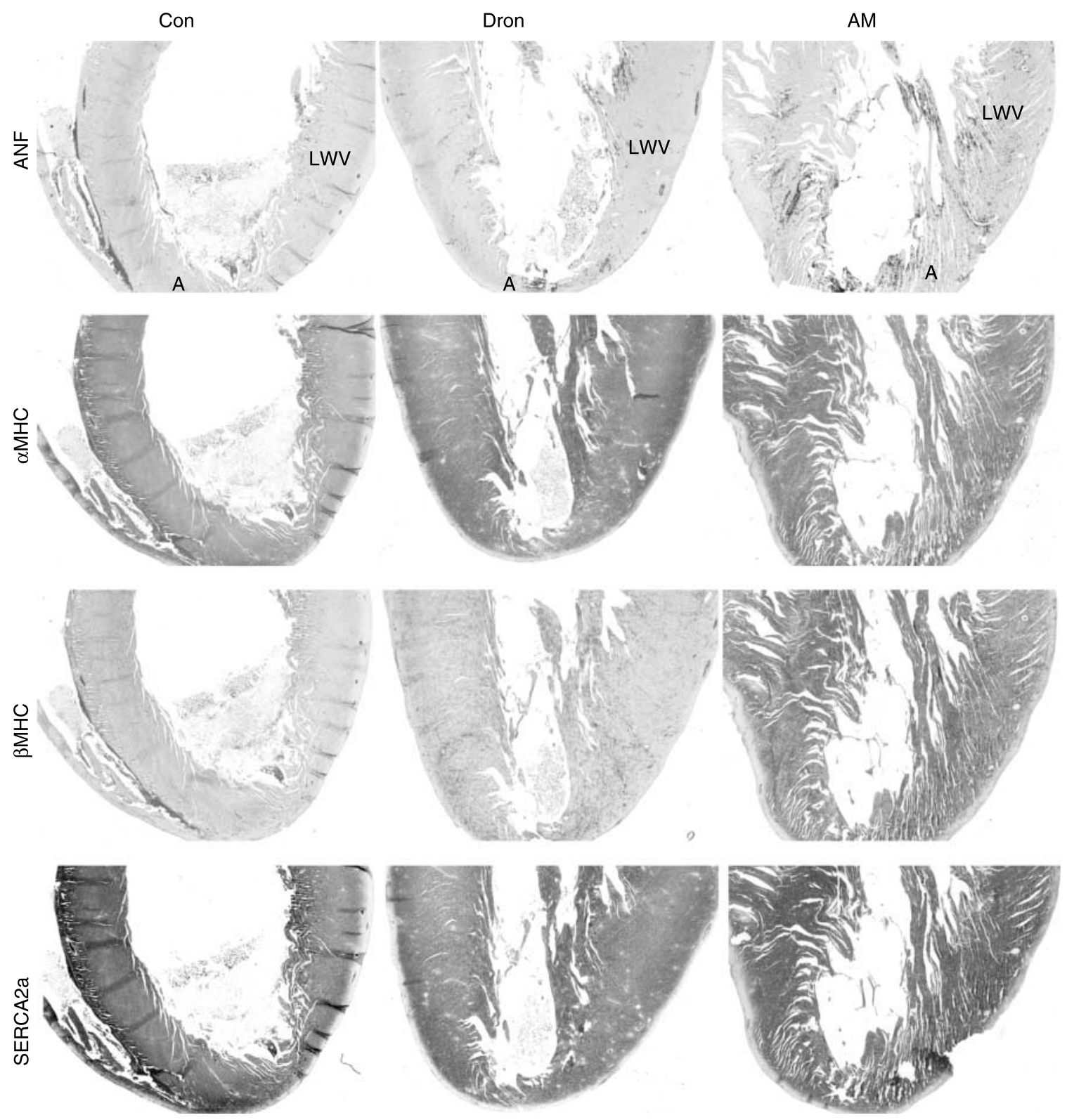

Figure 3 Cardiac mRNA expression of thyroid hormone-dependent genes. Overview of the left ventricle of control rats (left), Dron-treated (middle) and AM-treated (right) rats, stained with a sequence-specific, antisense probes, against ANF (first row), $\alpha \mathrm{MHC}$ (second row), $\beta \mathrm{MHC}$ (third row) and SERCA2a (fourth row). LWV, left ventricular wall; A, apex. All images are oriented in the same direction.

\section{Discussion}

Here, we study the expression of TH-dependent genes and TRs in relation to certain TH antagonistic effects of the class III anti-arrhythmic drugs AM and Dron. In an earlier paper, we characterised our animal model (11), and the changes in TH parameters seen in this study are essentially the same as in our former one. Furthermore, we showed in our earlier study that both AM and Dron decreased the heart rate and significantly increased the QTc interval (11). We now analyse the mRNA levels, by both in situ hybridisation and quantitative PCR, of a number of well-known $\mathrm{T}_{3}$-dependent genes as well as the levels of the TR isoforms $\alpha 1, \alpha 2$ and $\beta 1$ in the three different components of the rat heart, namely the RA, the LVW and the apex. Since we did not find any major discrepancies between the mRNA and protein levels of the TR isoforms in an earlier paper (21) using hyper- and hypothyroid mice, we concentrate on the mRNA levels of the TR isoforms in the present study.

In the present study, we observe that TR $\beta 1$ is downregulated by AM and Dron in all the heart components tested. This is probably due to a direct effect of the inhibition by these compounds of TR $\alpha 1$ (11). Indeed, 


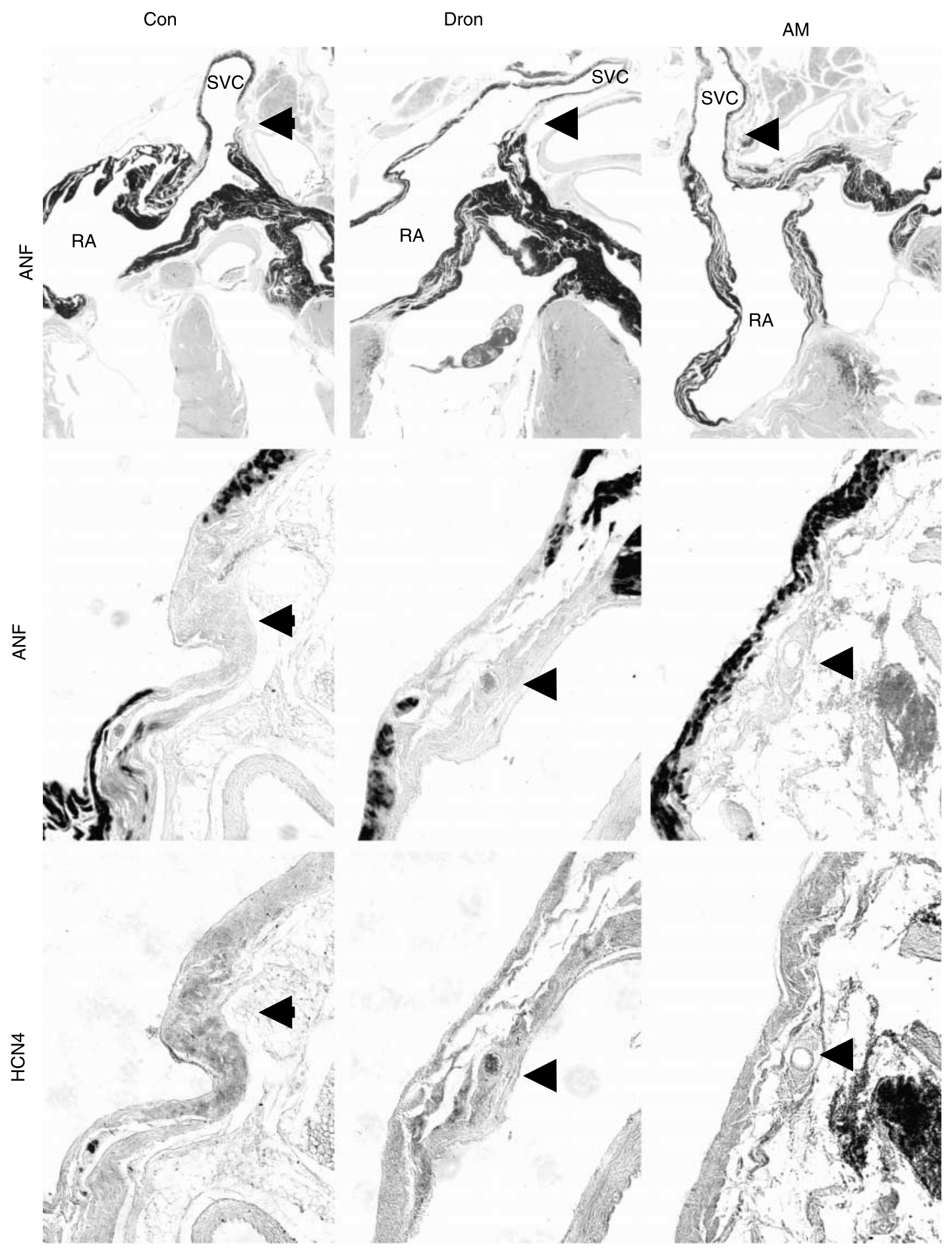

Figure 4 Cardiac mRNA expression of thyroid hormone-dependent genes in the right atrium and SAN. Upper row - overview of the RA and superior vena cava (SVC), stained with an ANF-specific, antisense probe, reveals ANF expression throughout RA and SCV (positive staining is in blue). The SAN is indicated by an arrow. Middle row - higher magnification shows similar sizes of the SAN between control animals (left), Dron-treated (middle) and AM-treated animals (right). The SAN is indicated by an arrow. Bottom row - HCN4 is expressed in the SAN of the animals of all groups. The SAN is indicated by an arrow. 
Sadow et al. (22) suggested that TR $\alpha 1$ also has a major role in cardiac regulation of both itself and TR $\beta 1$. We found a decreased expression of TR $\alpha 1$ in the RA, which contains the pacemaking components SAN and AVN due to both Dron and AM, which in case of AM has been shown before (23). The similarity of the effects of AM and Dron on TR isoform expression matches their ability to inhibit $\mathrm{TR} \alpha 1$, the isoform determining cardiac rhythm $(3,4)$. The down-regulation of TR $\alpha 1$ itself could be a result of more complicated mechanisms involving TR $\alpha 1$, TR $\beta 1$ and/or other (component-specific) factors (22). The latter suggestion is supported by our observation that $\mathrm{TR} \alpha 1$ is regulated in a componentand compound-specific manner. For instance, the effect of AM on the expression of TR $\alpha 1$ in the LVW differs from that of Dron. In this component, TR $\alpha 1$ is up-regulated by AM, which may signify a compensatory mechanism for the inhibition of $\mathrm{T}_{3}$ action due to the drug. Interestingly, the effects of AM on heart rate and contractility resemble those of the euthyroid TR $\beta 1$ knock-in mouse (24) and correlates with AM's ability to inhibit both TR $\alpha 1$ and TR $\beta 1$.

The ability of AM and Dron to differentially inhibit TR $\alpha 1$ and TR $\beta 1$ is reflected in their effects on TR-regulated cardiac gene expression. We could not find changes in the expression of $\mathrm{HCN} 4$ in the RA despite the bradycardia in the AM-treated animals (8). The bradycardia could, however, be explained by the non-genomic effects of AM on $\beta$-adrenoceptor density (25).

As expected, AM showed a trend to suppress the expression of the TR $\alpha 1$-dependent SERCA2a. In addition, $\alpha \mathrm{MHC}$ shows a trend of being down-regulated in the RA and it is decreased in the apex by AM but not in the LVW, correlating with the up-regulation of TR $\alpha 1$ in that compartment. Dron caused down-regulation of the TR $\alpha 1$-dependent $\alpha \mathrm{MHC}$ in the apex, which tallies with earlier reports showing that Dron changes $\alpha \mathrm{MHC}$ expression but not $\beta M H C$ and SERCA2a (6). The differences between Dron and AM could be due to AM's additional inhibition of TR $\beta 1$.

An interesting finding is that AM, but not Dron, causes an up-regulation of $\beta M H C$ and ANF. Since AM antagonises both TR $\alpha 1$ and TR $\beta 1$, our results support the earlier hypothesis that $\mathrm{TR} \beta 1$ has an important role for $\beta \mathrm{MHC}$ regulation (7). Furthermore, ANF was up-regulated specifically in the apex, subendocardial and pericoronarial cardiomyocytes, which form the PVCS, thus suggesting that TR $\beta 1$ may have a specific role there. The induction of $\beta M H C$ and $A N F$ as a result of AM treatment is reminiscent of the induction of these genes after heart failure and could indicate foetal reprogramming, as has been suggested by Kinugawa et al. (26).

Taken together, our results indicate that AM and Dron have similar effects on the expression of TR isoforms in the RA, which could partly contribute to their ability to decrease heart rate. On the other hand, the more profound effect of AM appears on TR- and
$\mathrm{T}_{3}$-dependent gene expression in the left ventricle suggests foetal reprogramming.

\section{Acknowledgements}

We thank J Daalhuisen for his help with the animal experiments.

\section{References}

1 Flamant F \& Samarut J. Thyroid hormone receptors: lessons from knockout and knock-in mutant mice. Trends in Endocrinology and Metabolism 200314 85-90.

2 Stoykov I, Zandieh-Doulabi B, Moorman AF, Christoffels V, Wiersinga WM \& Bakker O. Expression pattern and ontogenesis of thyroid hormone receptor isoforms in the mouse heart. Journal of Endocrinology 2006189 231-245.

3 Gloss B, Trost S, Bluhm W, Swanson E, Clark R, Winkfein R, Janzen K, Giles W, Chassande O, Samarut J \& Dillmann W. Cardiac ion channel expression and contractile function in mice with deletion of thyroid hormone receptor alpha or beta. Endocrinology $2001142544-550$.

4 Wikstrom L, Johansson C, Salto C, Barlow C, Campos BA, Baas F, Forrest D, Thoren P \& Vennstrom B. Abnormal heart rate and body temperature in mice lacking thyroid hormone receptor alpha 1 . EMBO Journal 199817 455-461.

5 Johansson C, Gothe S, Forrest D, Vennstrom B \& Thoren P. Cardiovascular phenotype and temperature control in mice lacking thyroid hormone receptor-beta or both alpha1 and beta. American Journal of Physiology 1999276 H2006-H2012.

6 Pantos C, Mourouzis I, Malliopoulou V, Paizis I, Tzeis S, Moraitis P, Sfakianoudis K, Varonos DD \& Cokkinos DV. Dronedarone administration prevents body weight gain and increases tolerance of the heart to ischemic stress: a possible involvement of thyroid hormone receptor alpha1. Thyroid 200515 16-23.

7 Kinugawa K, Yonekura K, Ribeiro RC, Eto Y, Aoyagi T, Baxter JD, Camacho SA, Bristow MR, Long CS \& Simpson PC. Regulation of thyroid hormone receptor isoforms in physiological and pathological cardiac hypertrophy. Circulation Research $2001 \quad 89$ 591-598.

8 Singh BN \& Vaughan Williams EM. The effect of amiodarone, a new anti-anginal drug, on cardiac muscle. British Journal of Pharmacology $197039657-667$.

9 Bakker O, van Beeren HC \& Wiersinga WM. Desethylamiodarone is a noncompetitive inhibitor of the binding of thyroid hormone to the thyroid hormone beta 1-receptor protein. Endocrinology 1994 134 1665-1670.

10 van Beeren HC, Bakker O \& Wiersinga WM. Desethylamiodarone is a competitive inhibitor of the binding of thyroid hormone to the thyroid hormone alpha 1-receptor protein. Molecular and Cellular Endocrinology $199511215-19$.

11 van Beeren HC, Jong WM, Kaptein E, Visser TJ, Bakker O \& Wiersinga WM. Dronedarone acts as a selective inhibitor of 3,5,3'triiodothyronine binding to thyroid hormone receptor- $\alpha 1$ : in vitro and in vivo evidence. Endocrinology $2003 \mathbf{1 4 4} 552-558$.

$12 \mathrm{Hu} \mathrm{K}$, Gaudron P \& Ertl G. Effects of high- and low-dose amiodarone on mortality, left ventricular remodeling, and hemodynamics in rats with experimental myocardial infarction. Journal of Cardiovascular Pharmacology 2004 44 627-630.

13 Pantos C, Mourouzis I, Saranteas T, Paizis I, Xinaris C, Malliopoulou V \& Cokkinos DV. Thyroid hormone receptors alpha1 and beta1 are downregulated in the post-infarcted rat heart: consequences on the response to ischaemia-reperfusion. Basic Research in Cardiology $2005100422-432$. 
14 Wiersinga WM \& Chopra IJ. Radioimmunoassay of thyroxine (T4), 3,5,3'-triiodothyronine (T3), 3,3', $5^{\prime}$-triiodothyronine (reverse T3, rT3), and 3,3'-diiodothyronine (T2). Methods in Enzymology 1982 $84272-303$.

15 Timmer DC, Bakker O \& Wiersinga WM. Triiodothyronine affects the alternative splicing of thyroid hormone receptor alpha mRNA. Journal of Endocrinology 2003179 217-225.

16 Moorman AF, Houweling AC, de Boer PA \& Christoffels VM. Sensitive nonradioactive detection of mRNA in tissue sections: novel application of the whole-mount in situ hybridization protocol. Journal of Histochemistry and Cytochemistry 200149 1-8.

17 Moorman AF, Vermeulen JL, Koban MU, Schwartz K, Lamers WH \& Boheler KR. Patterns of expression of sarcoplasmic reticulum $\mathrm{Ca}(2+)$-ATPase and phospholamban mRNAs during rat heart development. Circulation Research 199576 616-625.

18 Schiaffino S, Samuel JL, Sassoon D, Lompre AM, Garner I, Marotte F Buckingham M, Rappaport L \& Schwartz K. Nonsynchronous accumulation of alpha-skeletal actin and beta-myosin heavy chain mRNAs during early stages of pressure-overload-induced cardiac hypertrophy demonstrated by in situ hybridization. Circulation Research 198964 937-948.

19 Garcia-Frigola C, Shi Y \& Evans SM. Expression of the hyperpolarization-activated cyclic nucleotide-gated cation channel HCN4 during mouse heart development. Gene Expression Patterns 20033 777-783.

20 Zeller R, Bloch KD, Williams BS, Arceci RJ \& Seidman CE. Localized expression of the atrial natriuretic factor gene during cardiac embryogenesis. Genes and Development 19871 693-698.

21 Zandieh-Doulabi B, Platvoet-ter Schiphorst M, Kalsbeek A, Wiersinga WM \& Bakker O. Hyper and hypothyroidism change the expression and diurnal variation of thyroid hormone receptor isoforms in rat liver without major changes in their zonal distribution. Molecular and Cellular Endocrinology 2004219 69-75.

22 Sadow PM, Chassande O, Koo EK, Gauthier K, Samarut J, Xu J, O'Malley BW \& Weiss RE. Regulation of expression of thyroid hormone receptor isoforms and coactivators in liver and heart by thyroid hormone. Molecular and Cellular Endocrinology 2003203 65-75.

23 Shahrara S \& Drvota V. Thyroid hormone alpha1 and beta1 receptor mRNA are downregulated by amiodarone in mouse myocardium. Journal of Cardiovascular Pharmacology 199934 261-267.

24 Swanson EA, Gloss B, Belke DD, Kaneshige M, Cheng SY \& Dillmann WH. Cardiac expression and function of thyroid hormone receptor beta and its PV mutant. Endocrinology 2003 144 4820-4825.

25 Vassy R, Starzec A, Yin Y, Nicolas P \& Perret GY. Amiodarone has exclusively non-genomic action on cardiac beta-adrenoceptor regulation. European Journal of Pharmacology 2000408 227-232.

26 Kinugawa K, Minobe WA, Wood WM, Ridgway EC, Baxter JD, Ribeiro RC, Tawadrous MF, Lowes BA, Long CS \& Bristow MR. Signaling pathways responsible for fetal gene induction in the failing human heart: evidence for altered thyroid hormone receptor gene expression. Circulation 2001103 1089-1094.

Received 12 January 2007

Accepted 2 April 2007 